\title{
The Inclusion of Children with Autism in the Mainstream School Classroom. Knowledge and Perceptions of Teachers and Special Education Teachers
}

\author{
Glykaki Paraskevi \\ University of East London, London, UK \\ Email: evitaki.glykaki@gmail.com
}

How to cite this paper: Paraskevi, G. (2021) The Inclusion of Children with Autism in the Mainstream School Classroom. Knowledge and Perceptions of Teachers and Special Education Teachers. Open Access Library Journal, 8: e7855.

https://doi.org/10.4236/oalib.1107855

Received: August 13, 2021

Accepted: September 13, 2021

Published: September 16, 2021

Copyright $\odot 2021$ by author(s) and Open Access Library Inc.

This work is licensed under the Creative Commons Attribution International License (CC BY 4.0).

http://creativecommons.org/licenses/by/4.0/ (c) (i) Open Access

\begin{abstract}
The inclusion of children with special educational needs in mainstream schools is a global trend. The inclusion of children with special educational needs in these schools has been the subject of ongoing research and discussion in recent decades. Inclusion as a concept is concerned with the provision of education throughout the student world. Its most important condition is the transformation of schools into ready-made structures so that they can integrate all kinds of students. So, the purpose of the research is to explore the integration of children with autism in the general school class. More specifically, the views of general and special education teachers regarding the integration of students with ASD will be studied. The sample consisted of eighty-five (85) primary school teachers, including as a factor their knowledge in the inclusion of children with autism in general school. The quantitative approach was used to investigate these views and the questionnaire was used as a data collection tool. The results of the research process show that teachers have a positive attitude towards the inclusion of children with autism in general school. According to them, they believe that the integration in the general school will benefit them more in their socialization but also in the learning process.
\end{abstract}

\section{Subject Areas}

Special Education

\section{Keywords}

Inclusion, Autism, Special Education Teachers, Primary School Teachers, Integration 


\section{Introduction}

Autism is a chronic neurodevelopmental disorder first reported by Kanner and Asperger in 1943-1944. Autism has a complex cause and a multilevel clinical picture. People with autism have a lack of communication and social interaction and there is isolation with themselves. Students with autism are a heterogeneous group with some common characteristics. In recent years, the integration of children with autism has been an important issue in the educational community (general and special education). In society, people must live in harmony and each person must respect the existence of the other. Thus, this can be done through the acceptance of our fellow man through the educational system. Therefore, the school is a place where there is acceptance in every student and the school is a school for everyone [1].

Since the early $20^{\text {th }}$ century children with disabilities are divided according to their specificities and attending special schools, where they are intended to provide education to children with disabilities. In recent years there has been an increased interest in education for all students [2] [3]. Thus, we refer to the integration of children with special needs in the general school. By integration, we define the creation of a school that integrates all students. The purpose of integration is to provide equal educational opportunities to all students without discrimination. The theory of inclusion is that all students with disabilities should attend the same classroom as their classmates. Each student has their own educational needs and capabilities, which require a specific educational program. The inclusion of children with autism in general school is an issue where it is controversial and there are many views on the issue. The inclusion of children with autism creates many challenges and issues that need to be addressed. Children with autism face many problems when entering mainstream school. The risk of poor school adaptation for these children exacerbates the poor adaptive behavior of these children and thus integration becomes more difficult. Teachers are the key to the effective integration of students with autism. Their attitude and behavior are very important. The inclusion of these children in the mainstream school depends mainly on the will, mood, knowledge, perceptions and experience of the teacher [2] [4]. Thus, in this context, the purpose of this research is to investigate the views of teachers regarding the inclusion of children with ASD in general classes. More specifically, issues such as knowledge and implementation of existing legislation and the organization of integration will be studied. The ultimate goal is to enrich the academic child and to inform the educational community about the inclusion of children with autism in the general school. The research questions that will be answered through the collection of results are the following:

- Are teachers satisfied with their ability to organize an effective integration class for a child with ASD?

- Are teachers satisfied with their ability to promote the socialization of children with ASD?

- Are teachers satisfied with their ability to diversify their teaching to meet the 
needs of students with ASD classes?

- Are teachers satisfied with their ability to work with the tutor?

- What are the teachers' views on the education of children with ASD in the special school and what are the basic conditions for the inclusion of a child with autism?

- What are the teachers' views on the use of the medical and charitable model? So, in this paper, the researcher besides Chapter 1 that is the introduction has divided the research into 9 chapters. To begin with, Chapter 2 has to do with the integration. Consequently, it concludes the purpose of inclusive education, the implementation of integration in Greece, the concept of co-education and inclusive education, the forms of integration and the factors including integration.

Chapter 3 is about Autism Spectrum Disorder, so we will find a definition of ASD, historical background of autism, epidemiology of autism, the clinical picture and the characteristics of autism.

In Chapter 4, researcher talks about the school inclusion of children with autism. So, this chapter has to do with the role of a special education teacher, the role of a general education teacher and the possible challenges during the co-education, the inclusion of children with autism in general school, and the conditions for a successful inclusive education and how to achieve the integration of students with autism.

Chapter 5 is about relevant research that existed according to the current topic. Chapter 6 talks about the research methodology that the writer used. Chapter 7 has to do with the analysis of the upcoming results and finally Chapter 8 is the conclusion while in Chapter 9 some suggestions are proposed and some restrictions are mentioned.

\section{Theoretical Framework}

\subsection{Integration}

\subsubsection{What Is Integration}

The inclusion of children with special educational needs in mainstream schools has been the subject of ongoing research and discussion in recent decades. Inclusion as a concept is concerned with the provision of education throughout the student world. Its most important condition is the transformation of schools into ready-made structures so that they can integrate all kinds of students [5]. However, a few years before the discovery of the concept of integration, we were confronted with the social stigma of "abnormal" children, as society called it. During the $20^{\text {th }}$ century through continuous developments in psychology, in sociology and educational science the child becomes the center regardless of the emotional, physical and cognitive development where it is. Thus, for the first time in the mainstream school, mainly in foreign countries, we have the emergence of the concept of integration of "disabled" children [6].

In modern times, pedagogical science tends to enhance the joint education of children with and without special needs in order to create a school for all, in 
which children will not be discriminated against for mental, emotional, physical and linguistic peculiarities. Therefore, nowadays, children who have some peculiarities are not stigmatized as disabled or sick but are referred to as children with special educational needs [7]. More specifically, the process of integration in education is aimed at schools where they can meet the needs of children. The results of studies show that, if the necessary differentiation is made in the curricula and the way of teaching, children with special educational needs can develop in the mainstream school [8]. Therefore, attending mainstream school helps children with special educational needs but also children of formal development, since children of formal development understand the needs of these children and form a positive attitude towards disability [9].

\subsubsection{Purpose of Inclusive Education}

The main purpose of inclusive education is to create a school where students with typical and non-typical development can join, where each student has his or her own particularities and through this process will flourish through the school context. In this way all students are accepted by society, to live through its diversity and to stand out for it. Thus, the school and society must respectfully integrate these children [7]. Through inclusive education, children feel that they have a right to society and to gain a sense of belonging. The child through it should feel personally evolving and create a better future. The child is entitled to social, spiritual and personal integration in all areas of life. Through the positive elements of inclusive education, the student creates a background where he will significantly help him or her in social and school integration [10].

According to Kourkoutas [11] inclusive education attempts a school open to all, without categorizations and divisions and thus promotes a set of values. Regarding to the Greek educational system, integration is not a different method of teaching, but a different approach to education. It refers to a mainstream school where the core values are equality among students. In this way it eliminates diversity and highlights human rights in order to avoid the social exclusion of students with special educational needs [12].

\subsubsection{The Implementation of Integration in Greece}

The institutional and legal framework in which the integration of students with special needs in the mainstream school was developed and secured is mainly related to the post-colonial period in Greece. Thus, until 1981, the legislation on special education was limited and identical [13]. A radical change occurred with the enactment of Law 1143/1981 in 1981. Equality and equity were the basic foundations of this law for all citizens, which aimed to integrate people with disabilities into all sectors of society, having as a goal of their rehabilitation both socially and professionally [14]. However, this law was the product of strong negative criticism because in the end it did not contribute to the original policy of inclusion of people with disabilities but instead strengthened the distinction between "normal" and "abnormal" people, thus cutting off special education 
from general education.

The result of all these reactions was the enactment of correction in 1143/1981, law 1566/1985, also known as "anti-309", according to which special education is part of general education. This law refers to a separate chapter in special education, which is part of the broader context of general education. Thus, the desire to remove the segregation of children with or without special needs becomes apparent, resulting in the inclusion of the former in mainstream schools. Thus, the law of 1985 inaugurates a new period for special education in Greece adapted to European developments [15].

With the new law 2817/2000 [16], the mass integration of special education began in order to reintegrate people with disabilities [17]. Thus, the law of special education is redefined, emphasizing the common educational needs of people with disabilities, without focusing on the causes of their problems. In addition, the institution of "traveling teachers" was established (Government Gazette 78-A-14-3-2000) [16]. Then, the integration of people with special educational needs in the mainstream school is promoted, while the serious cases are limited to the special school. In order to achieve this goal, the creation of individualized education programs tailored to the needs of each child and at the same time strengthening the role of special teachers becomes possible [18].

In the new era of international and European developments, the Greek state voted for Law 3699/2008 [19]. The purpose of this law was to ensure equal opportunities for all citizens with disabilities and special educational needs, with the aim of their full integration. Article 2 (2) states that the educational services of the Special Education are diagnosed, evaluated and intervened with specialized and appropriate educational tools adapted to children with special educational needs, which are implemented by the local KEDDY and the public medical education services. SE mainly seeks the development of the personality and the utilization of the possibilities of the students with disabilities and special learning difficulties and has added co-education programs [20].

Finally, law 4547/2018 is the last law which refers to special education and training, as well as the reorganization of support structures at the levels of education. This law re-formulates and strengthens the term of inclusive education, since it emphasizes the treatment of the student's learning and psychosocial difficulties. These are dealt with in the appropriate way so that the student can integrate and follow the educational process through a pedagogical program where he is interested in it.

\subsubsection{The Concept of "Co-Education" and "Inclusive Education"}

The current trend that prevails in recent years in the field of special education in relation to the educational process of students with special educational needs has to do with their co-education within the school of general education. The terminology of inclusive education was first formulated in 1985 at the International Conference on Special Education in Salamanca, which aimed at the smooth co-existence and co-teaching of students with typical and non-typical develop- 
ment in mainstream schools of all grades. The process of inclusive education is an important process for the socialization of children with special needs, despite any difficulties that arise. The term inclusive education reinforces the position that education is a fundamental right for every child regardless of gender, individuality and origin and contributes to the creation of schools where they can smoothly integrate the entire student population and understand their educational needs and shape the educational program on them [21]. In inclusive schools each student is accepted and supported by all members of the school community. Therefore, the term co-education refers mainly when a child with special educational needs attends a mainstream school and receives any additional special support that the child needs in the classroom (parallel support) [22].

The term "inclusive education" is well known in pedagogical science. The Greek term for the word integration is translated as "inclusion", but it is not synonymous and thus cannot replace the meaning of integration in Greece. Thus, it can be referred to as "inclusive education or non-exclusion education" [2]. The adjective "inclusive" means inclusion and in pedagogical science is used for education that includes everyone and takes into account the needs and diversity of all students. The term "inclusive education" refers to an ongoing search and ongoing struggle with a focus on creating functional educational systems, as it maintains that each student is accepted and is supported by his classmates and other members of the school community [23].

\subsubsection{Forms of Integration}

Integration is mainly divided into three forms: spatial, social and functional. Spatial integration refers to cases where children with special or non-educational needs are together in the same school but in different buildings and there is almost no contact between the children. Then, the development of social interactions is the focus of social integration, but not in the classroom but through school events such as breaks, celebrations and excursions. With functional integration, all discrimination is eliminated. The student was included in the regular class and given the opportunity to participate in educational and social activities, providing him with some form of supportive assistance, i.e. a special educator or general education teacher. Finally, the purpose of functional integration is to help students with or without educational needs, guiding them in cognitive and social development, resulting in them becoming active members in both school and society [7].

As mentioned above, integration is found in various forms within the mainstream or special school. Integration becomes more effective in general education as its implementation is promoted. Thus, the forms of integration are distributed based on the possibilities of social contact. The forms of integration are classified in the regular class without the support of the special educator, in this form the integration of the student with special educational needs in the general class is done without the support and help of the special educator, in the regular class where students have disabilities mainly acoustic, visual and motor, they are 
provided with help and support, in the general classroom with a temporary auxiliary lesson, the regular classroom with a "touring" teacher, in this form in the classroom there is the teacher where he moves among the students and gives his help where needed [18].

In the form of the organization of the regular classroom, an additional classroom has been created where it provides additional supportive assistance to children with special needs in education, the so-called integration classroom with a dual form of teaching system. In this form there are two cases. In the first case there is special teaching staff and social educators, who offer support to students with or without special learning needs, following decisions of the school board. The second case is the supportive intervention by the aforementioned bodies but only to children with special learning needs. It is about the collaborative special class of mainstream school, in which children with special educational needs attend some lessons in the normal order but in particular, depending on the difficulty you have. Finally, in the separate special class of the mainstream school, the student does not attend classes in the general class but socializes with the other children during the break, depending on the degree of difficulty they have [18].

\subsubsection{Factors Influencing Integration}

Undoubtedly, there are some key factors that affect the smooth integration. Initially, one of the key factors is the type of special needs of each student, as well as any additional weaknesses. All of these must be examined and evaluated with great precision, so that the student has the opportunity to take part in all classroom activities. In this way the child will feel safer and accepted by the school community [24].

Then another key factor is school. During the arrangements that need to be made by a mainstream school where children with special educational needs are included, it is very likely that general and specific problems will arise. These problems have to do with the organization of the school, with its operation, the architecture of each school, the configuration of the classrooms, the staff and of course the curriculum. A major difficulty that arises is the availability of teacher time to students with special educational needs and to standard students. The number of students in the classes where children with non-typical development are included should not exceed 25. The syllabus and timetable, teaching methods and the overall organization of the school should be adapted to the needs of children with special educational needs. Medical, psychological and social services must be located in the mainstream school to support the student with special educational needs and to work with the teaching staff. Of course, an integral part is the presence of the special educator in the mainstream school, in order to monitor the child with special educational needs and to support and assist the general education teacher [25].

Finally, one of the key factors influencing integration is parents. The attitudes of the parents differ depending on the social perceptions and the degree of diffi- 
culties of the children. Parents do not want their children to be in the protective environment of the special school but on the other hand they do not feel safe when their child enters the mainstream school as they are afraid that their child will lag behind the rest of his classmates in some activities. In these situations, parents need counseling services to be able to understand the problems that may arise during integration. Of course, it is important for parents to participate in the educational process in order to feel safe and adequate themselves [25].

\section{Autism Spectrum Disorder}

\subsection{What Is Autism Spectrum Disorder}

Leo Kanner and Hans Asperger have reported that the concept of autism comes from the Greek word "self”. Autism is defined as a pervasive developmental disorder that affects many areas of a person's life. As a result, there is no homogeneity in the clinical picture of autism, as it ranges from milder to more severe forms. According to the DSM-IV (1993) [26] which is the diagnostic and statistics of mental disorders manuals, autism is defined as a pervasive developmental disorder that has a developmental disorder where it manifests itself in social interaction, communication and repetitive behavior.

In 2013 the renewed DSM-V (2013) [27] was published where many changes were made in the categorization and diagnostic criteria of autism. Thus, there are no longer subgroups but a common group defined as Autism Spectrum Disorder (ASD). People with autism have not developed the areas of communication, social relationships, interests and activities [1]. All this does not allow these individuals to interact and prevents them from entering society smoothly. According to the International Commission on Autism, there seems to be a complex impairment that affects the sensory part, as well as the cognitive part (logic and organization of thought) [28] [29].

In addition, the most obvious characteristics of people with autism are social interaction and socio-emotional development. Children with autism at an early age show a lack of emotional and social reciprocity, which manifests itself in the absence of eye contact, lack of interest in others, difficulty understanding the feelings and expressions of others [30]. Autism spectrum disorders (ASD) are complex neurodevelopmental disorders that to this day are largely of unknown cause. ASD epidemiological data show that its increase is from $1 \%-3 \%$ in children and adolescents and concerns approximately 7.6 per 1000 people worldwide. ASD manifests itself from the beginning in the life of the individual, since there are indications from infancy and strengthens in adolescence and adulthood. We find it mainly due to mental disability and other diseases, such as epilepsy, depression, etc. In recent years, the diagnosis of people with autism spectrum disorder is increasing, since the etiology of ASD is of great research interest [31].

\subsection{Historical Background of Autism}

The term autism first appeared in 1911 by the Swiss psychiatrist Bleluer. The Bleluer introduced the word autism to show a symptom of schizophrenia which 
main feature is the close of my person himself, which the difficulty of the individual to socialize with other people and remove from reality. The Swiss psychiatrist reported that these individuals limit their interpersonal relationships, noting that it was such a severe and extreme limitation that it leaves everything outside of itself [32].

In 1943 in America the child psychiatrist Leo Kanner, having observed a group of children, distinguished the great difficulty of communication and the manifestation of apathy for what is happening in the wider social space. After a year, the Austrian pediatrician Hans Asperger, after watching children with the same characteristics, gave the diagnosis of "autism". But the disorder was not recognized by physicians until the $20^{\text {th }}$ century. Then autism became a special disorder [33]. The Kanner in Baltimore and Asperger in Vienna began to record cases of "strange" children which showed almost same features. The two scientists concluded that there is a congenital anomaly, which was related to speech problems, communication and different ways of thinking from other people.

In 1976 Lorna Wing referred to people with autism and the problems they face with socialization, communication and imagination [34]. Then, in the "50s, many child psychologists monitored children with autism, until the" 70 s, the first research on the cause of autism began. Over the years, some researchers have examined the mother's emotional affection for the child, calling the mother a "refrigerator." Having noticed that autism occurred regardless of the psycho-emotional state of the parents, this theory was refuted.

In the 1980s, autism was included in the American Psychiatric Association (DSM) Diagnostic and Statistical Manual. In addition, new research suggests that autism is due to heredity, the father's age, the mother's smoking during pregnancy, and certain vaccines given to children. However, none of them were accepted by the scientific community and so to this day we do not know the real causes of this disorder [35].

\subsection{Epidemiology of Autism}

During these years, many epidemiological researches are carried out where they serve both in theoretical and practical level. These studies are useful because researchers identify the prevalence of the disorder and thus contribute to the knowledge about the development and etiology of autism. Epidemiological rates often differ. In a general context, autism occurs in about 60 children per 10,000 under the age of 8 and 10 - 30 per 10,000, where they are associated with autism and other pervasive developmental disorders. Boys are 3 - 4 times more likely to be diagnosed with autism than girls. Then, $2-5$ out of 100 children born as twins develop autism. Research shows that the largest percentage of people with autism is $70 \%$ where they also have mental retardation [36].

\subsection{Clinical Picture and Characteristics of Autism}

Children with autism have severe developmental disabilities and difficulty communicating. The problems they face in the expression and comprehension of 
speech are obvious. Thus, their speech may be gradual or they may not communicate for long intervals. In addition to speech retardation, people on the autism spectrum may not be able to understand the communication context of a conversation, i.e. if metaphorical speech is used, irony, implied words, as well as evolutionary communication, facial expressions, tone of voice and eye contact. Another special feature of children with autism is hoarseness, more specifically the repetition of words or phrases with a constant tone. The hoarseness becomes more pronounced in stressful situations.

In addition, people with autism create their own vocabulary from words and phrases [37]. Children with autism spectrum disorders lag behind in social interaction, i.e. they are more isolated and refuse contact with a lot of people. They also have a lack of empathy where they cannot understand the other person's emotional state. The child with autism adopts strange ritual behaviors where it is done in a repetitive and stereotypical way. The term stereotype describes the repetition of movements such as rotating around oneself, continuing to move the arms and walking on the toes. These are just a few of the stereotypes that mostly these children display when they feel embarrassed, anxious, and excited. Then children with autism are more likely to injure themselves (e.g. by biting their hands). Every change in the environment and the program causes them upset, crying and aggression. Most children with autism always follow the same path, sit in the same position at the table and prefer the same food. So, they follow the routine without any change. Then these children have limited interests and activities. Therefore, their game is dominated by repetitive movements [38].

\section{School Inclusion of Children with Autism}

\subsection{The Role of the Special Education Teacher}

The inclusion of children with special educational needs in mainstream school is a global trend. The teacher plays an important role in the successful implementation of inclusive education. Initially, the special educator is an integral part of this process. Thus, in order for the integration to take place in the maximum possible way, the special education teacher takes on various roles, such as teaching assistant, supervisor, coach, mentor and many more. The task he/she is called to do is to connect his/her knowledge with the needs of the child and his/her experiences with the respective teaching units where he/she will need to do, to make a correct evaluation of the educational practices and the effectiveness of his/her work as well as to cooperate with the rest of the scientific staff to achieve the best outcome for the integration of these children. Finally, the main role is played by the cooperation that the special education teacher will develop with the children's parents, the mutual respect that will be created between them for their common goal, the school and social integration of the students [39].

\subsection{The Role of the General Education Teacher and Possible Challenges during the Co-Education}

The general education teacher is an important factor for the integration of stu- 
dents with special educational needs in the mainstream school. After all, the general education teacher through their knowledge, his/her will, his/her mood and his/her experience can help the children in their full integration. Research has shown that inclusive education is likely to fail when teachers do not have a positive attitude towards integration. In conclusion, the attitudes of general education teachers have a significant impact on an integration class [40].

As far as the inclusion of students with autism in the mainstream school is concerned, teachers need to have scientific training for the co-education of children. Thus, they should be able to create alternative teaching methods and an appropriate curriculum tailored to the needs and particularities of children with autism. The teacher through the integration should take care of the change of attitudes of the classmates in order to accept the children with autism. Then there should be good cooperation between the teacher and the parent for the smooth integration of children with autism.

The role of the general education teacher becomes even more demanding since he/she must approach children with autism among the children of normal development [41]. He/She should understand the different needs of his/her students, to adapt his/her environment properly with the appropriate stimuli so that the student with autism finds interest and as much as he/she can be autonomous in the classroom but also to focus on the emotional and social field of children. Of course, in this context, tensions and difficulties are created where they create stress for the teacher on how to deal with them. In this context, general education teachers face various challenges in relation to the inclusion of children with autism in general school.

These challenges have to do with socio-structural barriers and the creation of an inclusive environment. One of the important and frequent problems that the general education teacher faces is his/her inability to recognize the unique way of thinking of children with autism and how they perceive the stimuli of space. Teachers, although aware of the peculiarities of these children, have the wrong conclusion that they act in the same way as normal children; they cannot comprehend the difficulty of these children. Children with autism and children with formal education show common points of behavior so that general education teachers have difficulty and thus exclude children with autism. Therefore, teachers need more training and support to enhance inclusive education [11].

\subsection{The Inclusion of Children with Autism in General School}

The school inclusion of children with autism is considered particularly important. Through the educational process, people learn values, attitudes, and skills in order to integrate into society. Thus, the integration of children with autism in mainstream school offers experiences and a first experience for their social integration. However, this view is not universally adopted since school integration does not have the social as a necessary sequence, but is considered a precondition. Children with autism who are in the mainstream class have a higher level of social coexistence and support and higher educational goals in contrast 
to children where they are in special school [42].

Therefore, enrolling children in a mainstream school sets higher goals. Through interaction with typically developing children, children with autism have the opportunity to come into contact with acceptable social behaviors that will positively influence their trial behavior. In the context of integration, children with autism improve their functional play as opposed to a separate context. Research has also shown that children with autism do not exhibit such strongly characteristic behaviors when interacting with typically developing children. Additional research has shown that through cognitive education, children's cognitive performance is improved. The positive effect occurs not only in children with autism but also in typical children since through coexistence they gain experiences and accept diversity and become aware of the issues of special education [10].

\subsection{Conditions for Successful Inclusive Education and Achieving the Integration of the Student with Autism}

The inclusion and ability of a child with autism to integrate into a peer group depends on the duration of the early intervention. Also, the sensitivity and readiness of the teacher but also the smooth cooperation with the parents is the main basis for a successful integration. The attitude of teachers and the flexibility of the school such as the building infrastructure, the appropriate equipment, the teaching material and the specialized staff, these are key factors for the integration of children with autism in the general school. The school inclusion of children with autism can be implemented under the following conditions: early and valid diagnosis, early supportive intervention and the involvement of parents in early supportive intervention procedures [43] [44].

The diagnosis of a child with autism by the competent bodies and the decision to join a class is the first step for the educational program. The integration must start from the first school years of the child in order to have the right reaction. Young children have not come into contact with exclusion and with proper education they will be able to accept and understand diversity and thus reduce their rejection. The main criteria for the success of the integration are the teachers, their attitudes and behaviors, their education, the cooperation of the parents with the school and most importantly the cooperation between the general and special educators. Mentioning a successful integration, teacher training is an integral part of it. Teachers must be constantly trained for the special educational needs but also for the new educational practices for these children. The right conditions for integration are an important opportunity for a society for all [45].

\section{Relevant Research}

The inclusion of children with autism in mainstream school is always of interest in the field of science. Indicatively, in the research of Laze [46] the knowledge and perceptions of the teachers of general and special education for the integration of children with autism in the regular class of the mainstream school were 
studied. The purpose of this study, in addition to investigating teachers' views on integration, was to investigate whether the demographics of the participants affect their knowledge in relation to the integration of children with ASD. The method used is the quantitative and the research tools the questionnaires.

Therefore, 150 questionnaires were distributed to general and special education teachers. The results of the research showed that most teachers consider the right of people with autism to be educated in general school classes, since they are provided with more opportunities. Finally, it was observed that those teachers who have a postgraduate degree in special education, etc. have more knowledge on the issues of autism and inclusion.

A similar study was conducted by Nerantzidou [47] with the aim of investigating how children with autism are treated in the integration departments. $\mathrm{Qu}$ alitative research was used as a methodological strategy, with semi-structured interviews. The sample of the research was 15 kindergarten teachers of integration departments and 5 kindergarten teachers. According to the results of the research, kindergarten teachers have difficulty in co-educating children with autism. In addition, it appeared that there is no frequent cooperation of general and special education kindergarten teachers. While kindergarten teachers do not seem to be involved in activities together and adapt the program to the needs and abilities of all children.

The research conducted by Exarchou [48] aimed to investigate the issue of education of students with autism spectrum disorders and more specifically to study the views of general and special education teachers on inclusive education-inclusion of students with ASD in the general classroom school. The qualitative method was used in this research, so 16 semi-structured interviews were conducted with primary school teachers. The results of the research showed that teachers have a positive view on the inclusion of children with autism in the mainstream school, as they speak of a school for all students where all children can be educated without segregation. It is worth mentioning that the teachers in this research mention the factors that can affect the integration of these children such as the lack of material and technical infrastructure, the lack of teacher training and the cooperation of general and special education teachers.

A related study was conducted by Majoko [49] where she explored the views of primary school teachers in Zimbabwe regarding the inclusion of children with autism in mainstream school. The method used was qualitative with 24 semi-structured in 24 teachers working in primary schools. The results of the research showed that despite the uncertainty of the teachers about the inclusion of children with autism in the mainstream school, they had positive attitudes. They also said that it would help to integrate a school psychologist to help themselves and children with autism for their smooth integration into the mainstream school. All teachers unanimously stated that there should be continuous specialization on inclusion and autism.

The survey of Bosch [50] investigated the attitudes of teachers of secondary 
education and special education teachers in connection with the integration of children with autism in mainstream settings. The method used is the quantitative and the research tool the questionnaires where they were distributed on a Likert scale. Thus, 90 questionnaires were distributed to secondary school teachers and special education teachers. The results of the research showed that secondary school teachers and special education teachers consider the inclusion of children with autism in general school very important as they believe that it will benefit them in many areas of their lives.

In conclusion, the above research shows that teachers have a positive attitude towards the inclusion of children with autism in mainstream school. According to them, they believe that the integration in the mainstream school will benefit them more in their socialization but also in the learning process. In most research, teachers report continuing education on inclusion and autism.

\section{Research Methodology}

\subsection{Educational Research}

Educational research aims to solve educational problems that aim to add new knowledge to the organized set of scientific knowledge that exists in the educational system [51]. Educational research is implemented by applying two methods of qualitative and quantitative. Those two methods enable the researcher to approach a research field and focus on it.

\subsection{Methodological Approach}

Quantitative methodology was used in the research conducted. Quantitative research is used to extract information from a part of society where its results represent the entire population. Thus, the purpose of quantitative analysis is to discover the causes of changing social phenomena through numerical analysis. Through this type of research, the researcher starts from an existing theory and seeks an answer. This answer comes through figures. The use of quantitative research is based on the projection of data through numbers and distribution tables, thus, its main purpose is to gather information about perceptions and opinions about the behavior of a sample.

In addition, quantitative research can be a combination of two or more variables where it is possible to approach a larger part of the population and data are collected using questionnaires, scales and achievement tests [52]. The aim of quantitative research is to generalize, that is, to arrive at generalizations and empirically grounded theories. Finally, according to the quantitative methodology, any research must meet the criteria of validity, representativeness, reliability and objectivity, so that the researcher can argue that the findings can be generalized [53]. The specific method was chosen for the research that was conducted because the researcher wants to focus in depth on the views of general and special education teachers regarding the inclusion of students with ASD in the mainstream school. 


\subsection{Sampling}

The sample was collected by convenient sampling. Specifically, in the research that was conducted, the sample was collected from the wider social environment of the researcher. Thus, according to Zafeiropoulos [54] in convenient sampling, the formation of the sample depends on the accessibility of the researcher to the population data. Additionally, the researcher selects his sample according to the people close to him. The participants in the present study are 200 general and special education teachers.

\subsection{Research Sample-Participants}

The research population consists of special and general teachers of primary education mainly in the area of Athens. The sample consists of 85 men and women from both special and general education. The questionnaire was developed electronically via Google Forms and sent via social media and email.

\subsection{Research Tool-Questionnaire}

The research tool used in this study is the questionnaire. The main research tool of the quantitative method is the questionnaire. According to Vamvoukas [55] "The questionnaire is a set of written questions related to a problem, which the researcher addresses uniformly to the subjects of the sample in order to gather the necessary information." The questionnaire is prepared for each survey specifically and applies only to it. Its design and construction is particularly difficult as is the critical phase of the research process. The specific questionnaire will be used in this research with some minor modifications: "Investigation of the views of teachers of the General class for the integration of students with Special Learning Needs" [56]. In more detail in the first part of the questionnaire, participants will have to answer 5 demographic questions such as gender, position, years of service, basic studies and postgraduate studies. In Part B there are closed-ended questions, in which the subject's freedom is limited to a minimum as he/she is asked to answer Likert-type questions ( 1 = Strongly disagree, $5=$ Strongly agree). More specifically, in part B the questions concern the teachers' views on integration and the satisfaction they feel for their ability to implement integration (36 questions). The questionnaire has been tested for reliability and its Cronbach Alpha coefficient is high as it is set at $\alpha=70$.

\subsection{Research Procedure}

The present research was conducted from February to March of the academic year 2021. All teachers were informed through the participant information form, where they were informed about the purpose of the research, the anonymity and protection of their personal data, as well as their voluntary participation in the research process. The average time taken to complete the questionnaire was 15 20 minutes.

Due to the situation in the country with the pandemic (SARS-COV-2) the questionnaires were made through Google Forms and were distributed electron- 
ically on social networks and in electronic training groups. The teachers had all the information of the researcher for questions and explanations. The process went smoothly.

\subsection{Data Analysis}

Quantitative data analysis was used for the needs of the present study. More specifically, the SPSS (Statistical package for Social Sciences) was used to record and analyze teachers' views. In addition, descriptive statistics, averages and standard deviations were computed, as well as inductive statistics for hypothesis tests to answer key research questions.

\subsection{Issues of Validity and Reliability}

The measurement of attitudes and behavior in the social sciences aims at the numerical rendering of human characteristics by conventional rules. The psychometric scale is defined as a tool for collecting behavioral observations that can be generalized. Thus, there are two basic criteria for ensuring valid research results, reliability and validity. The validity of the content is paramount in the collection of data of a research and examines whether the content of the proposals conceptually covers the range of the variable being researched [57]. When repeated measurements in the same sample at the same time points bring the same consistent results, they prove reliability.

Internal reliability testing is required when a measurement tool is first applied to a specific population with different demographic and occupational characteristics. The internal consistency reliability expressed by the index Cronbach's alpha (a) is a key issue for the development of a reliable scale. The values of the coefficient range from 0.00 to 1.00 with a reliable measurement considered to be of the order of 0.80 . It is worth noting that a questionnaire when it meets the validity criterion is then automatically reliable [58]. In the present study, the validity and reliability of quantitative data managed by the researcher is ensured through careful and appropriate sampling by a representative number of the population (approximately 200 general and special education teachers).

\subsection{Morality and Ethics}

In the field of research, there has been an increasing concern in recent years about the techniques adopted by researchers and their structures for the collection of research data, as well as the way in which this data is used after the completion of research. The ethical problems that arise are directly related to the type of research and the choice of research methodology and how the data will be used. The researcher should follow the rules of ethics of the scientific community, ensuring the participants their right to protection, privacy and reliability [59]. Thus, adherence to ethical issues plays a crucial role in any research.

Ethics are an important element of research, from the conception of the idea to the publication of the results. A basic principle of ethics is the conscious consensus that protects and respects the right to freedom and self-determination. 
More specifically, it contains the procedures by which individuals choose whether to take part in a survey after being informed of events that may influence their decisions. The importance of this principle is obvious in the initial stage of the research program which is related to the access to the institution or organization when the research is to be carried out as well as to the acceptance of the program by those whose permission is required.

In the research that was conducted, the participants were informed through the information form of participants about the purpose of the research and that their personal data was preserved. They also filled in the participants' consent form to formally give their consent for their participation in the research. Another fundamental principle of ethics is anonymity. In particular, information passed on by participants should not reveal their identities. This principle is a guarantee of respect for the privacy of participants. Remarkable is still the principle of confidentiality, as it is a way of protecting the right to privacy [60].

In the research that was carried out, the researcher coded the personal data of the participants and at the end of the research they were destroyed. It is important to note that participants had the researcher's personal information about problems during the research they could contact. It should not be overlooked, however, that the participants' relationship with the researcher emerges as a power relationship arising from the research and is directly intertwined with ethical issues. Ethics refers to rules of conduct, compliance with a code of conduct, or a general set of principles and behaviors.

For the most part, the terms of morality differ from those of ethics. Although both terms refer to what is good, bad, right or wrong, ethics refers to "general principles of conduct", while morality refers to "whether a particular act is consistent with the accepted notion of right or wrong or not". Right or wrong, good or bad are not easily identifiable concepts and this is because two worlds are involved in research: the world of what is (objective description of a situation) and the world of what should be according to which behavior is stated ethically permissible (researcher values).

These dilemmas, which have the requirement by the researchers to be able to balance between the search of the truth and the rights of subjects, are known as a cost - benefit ratio [60]. It is important to mention that plagiarism, misappropriation of foreign research and the presentation of false results contribute to the violation of morality and ethics [57].

\section{Analysis of Results}

This chapter presents the results of the questionnaires ( 85 in total) that emerged from the descriptive statistical analysis of the data using the statistical program SPSS. The research yielded interesting results in the field of integration.

\subsection{Demographics}

The analysis of the aggregate data of the questionnaires begins with the reference 
of the demographic data that accompany this research. The following table shows these elements (Table 1).

The study involved 85 primary school teachers, of which $84.7 \%(\mathrm{n}=72)$ are graduates of the Pedagogical Department of Primary Education, while 15.3\% $(\mathrm{n}=13)$ are graduates of a University Abroad. As for the report on postgraduate studies, 65.9\% $(\mathrm{n}=56)$ have a Master's Degree in Special Education, $11.8 \%(\mathrm{n}=$ 10) have a Master's Degree in School Psychology and 2.4\% $(n=2)$ have a Master's Degree in Education. In the present study the largest percentage of participants were women with $84.7 \%(n=72)$, compared to men with $15.3 \%(n=13)$. As for the reference for the years of service with $11.8 \%(n=10)$ are the teachers with 1 - 5 years of service. The largest percentage had teachers with 6-10 years of service with $42.4 \%(n=36)$, with $11-15$ years of service held $41.2 \%(n=35)$ and finally $4.7 \%(n=4)$ are teachers with $16-20$ years of service. Finally, the largest percentage of teachers with $76.5 \%(n=65)$, who participated in the survey hold the position of general class teacher within the school, while $11.8 \%(n=10)$ hold the position of Principal and Assistant of the Director.

\subsection{Results of Research Questions}

In this chapter the research questions will be answered through the results of the questionnaires. Initially, the questionnaire utilized the questions that focus on the knowledge that primary school teachers have about children with autism and the implementation of legislation. More specifically, it seems that teachers are

Table 1. Sample of the research.

\begin{tabular}{|c|c|c|c|}
\hline Variables & Categories & Frequencies & $\begin{array}{l}\text { Fig. } \\
\text { Frequencies }\end{array}$ \\
\hline \multirow{3}{*}{ Sex } & Man & 13 & 15.3 \\
\hline & & & \\
\hline & Woman & 72 & 84.7 \\
\hline \multirow{3}{*}{ Position } & Director & 10 & 11.8 \\
\hline & Assistant manager & 10 & 11.8 \\
\hline & General Class Teacher & 65 & 76.5 \\
\hline \multirow{5}{*}{ Years of service } & $1-5$ & 10 & 11.8 \\
\hline & $6-10$ & 36 & 42.4 \\
\hline & & & \\
\hline & $11-15$ & 35 & 41.2 \\
\hline & $16-20$ & 4 & 4.7 \\
\hline \multirow{2}{*}{ Basic studies } & $\begin{array}{l}\text { Pedagogical Department of Primary } \\
\text { Education }\end{array}$ & 72 & 84.7 \\
\hline & University Abroad & 13 & 15.3 \\
\hline
\end{tabular}


well aware of the legislation and how they can use it to operate within a general school.

More specifically, as shown in the table below (Table 2), 52.9\% of teachers identify a child who is likely to have autism, this has to do with the fact that younger teachers, as shown by the demographic data of the research, are being trained more and more with postgraduate studies and training seminars in relation to special education than in the constant study of new research, teachers to be more qualified and can more easily identify the characteristics of a child with autism. Then, $63.5 \%$ of teachers follow the referral process to assess a child who may have autism.

Teachers seem to be very familiar with the legal framework regarding the assessment of children with autism. Since according to law 369/2008 the purpose is to ensure equal opportunities for all students with disabilities and special educational needs, through the SE to diagnose, evaluate and intervene with personalized educational tools, where implemented by KESY (former KEDDY) and by public medical education services. $69.4 \%$ develop an individual education program for a child with autism.

Therefore, the research findings show that teachers stress the need of these children for an individualized education and a modern education program to help children with autism. $64.7 \%$ of teachers educate children with autism who are enrolled in general school. Thus, teachers show that they are in favor of inclusive education and that children with autism should be included in the mainstream school and that this benefits children with autism. Finally, $65.9 \%$ of teachers identify the main educational goals they should set for a child with autism. Thus, teachers seem to be trained and able to set educational goals for a child with autism so that he or she can adapt within the school context and respond to school activities.

The first research question was "Are the teachers satisfied with their ability to mount an effective integration classroom for a child with ASD?" To answer this research question, the category of questions from the questionnaire that focuses on the organization of integration was used. More specifically, through the answers as shown in Table 3, teachers can organize effective integration of

Table 2. Knowledge and implementation of legislation.

\begin{tabular}{cccccccc}
\hline $\begin{array}{c}\text { I neither } \\
\text { agree nor } \\
\text { disagree }\end{array}$ & Agree & $\begin{array}{c}\text { Strongly } \\
\text { Agree }\end{array}$ & $\begin{array}{c}\text { Average } \\
\text { Price } \\
(\mathrm{m})\end{array}$ & $\begin{array}{c}\text { Standard } \\
\text { Deviation } \\
(\mathrm{S} . \mathrm{D})\end{array}$ & Skewness & Kurtosis & \\
\hline Q. B1 & $3.5 \%$ & $43.5 \%$ & $52.9 \%$ & 4.49 & 0.57 & -0.57 & -0.67 \\
Q. B2 & $5.9 \%$ & $63.5 \%$ & $30.6 \%$ & 4.25 & 0.55 & 0.04 & -0.31 \\
Q. B3 & $3.5 \%$ & $69.4 \%$ & $27.1 \%$ & 4.24 & 0.50 & 0.37 & -0.12 \\
Q. B4 & $8.2 \%$ & $64.7 \%$ & $25.9 \%$ & 4.15 & 0.61 & -0.41 & 1.13 \\
Q. B5 & $4.7 \%$ & $65.9 \%$ & $29.5 \%$ & 4.25 & 0.53 & 0.17 & -0.26 \\
\hline
\end{tabular}


children with autism.

More specifically, $63.5 \%$ organize an effective integration of a child with autism in the classroom. Thus, as the literature mentions through inclusive education, it is possible for every student where he has peculiarities to flourish within the school context. In this way all students are accepted by society. Through inclusive education, children feel that they have a right to society and thus acquire a sense of belonging [10]. Then, $65.9 \%$ of teachers organize an effective integration of a child with autism in school. At this point it seems that teachers promote the "school for all", where each child enters the learning space without being distinguished by mental, linguistic, physical and emotional specificity.

Inclusion in education is the process where a school tries to meet the needs of students [8]. 67.1\% answered that they create effective learning conditions for a child with autism. Teachers through these conditions help the socialization of these children, and help them to intensify smoothly in the school process and through a personalized program the child with autism can learn more easily. $65.9 \%$ of primary school teachers said that they adapt to any kind of special need that a child with autism may have in the classroom.

Teachers face many challenges. The teacher should be aware of the different needs of his/her students and adapt his/her environment properly with appropriate stimuli so that the student with autism finds interest in the classroom. With a percentage of $68.2 \%$ it seems that teachers can effectively include a child in the Language lesson and $64.7 \%$ in the Mathematics lesson. $67.1 \%$ stated that they are able to effectively include a child in social studies classes. The teacher is called to connect the knowledge with the needs of the child and his/her experiences with the respective teaching units where he/she will need to do, to properly evaluate the educational practices and the effectiveness of his/her work [39].

The second research was "Are teachers satisfied with their ability to promote the socialization of children with $A S D$ ?" To answer this question, questions focusing on the promotion of socialization were used. More specifically, from the

Table 3. Organization of integration.

\begin{tabular}{ccccccccc}
\hline $\begin{array}{c}\text { I absolutely } \\
\text { disagree }\end{array}$ & $\begin{array}{c}\text { I neither disagree } \\
\text { nor agree }\end{array}$ & Agree & $\begin{array}{c}\text { Strongly } \\
\text { Agree }\end{array}$ & $\begin{array}{c}\text { Average Price } \\
(\mathrm{m})\end{array}$ & $\begin{array}{c}\text { Standard } \\
\text { Deviation (Sd) }\end{array}$ & Skewness & Kurtosis \\
\hline Q. B1 & $1.2 \%$ & $7.1 \%$ & $63.5 \%$ & $28.2 \%$ & 4.18 & 0.66 & -1.23 & 5.38 \\
Q. B2 & $1.2 \%$ & $8.2 \%$ & $65.9 \%$ & $24.7 \%$ & 4.13 & 0.65 & -1.19 & 5.40 \\
Q. B3 & $1.2 \%$ & $5.9 \%$ & $67.1 \%$ & $25.9 \%$ & 4.16 & 0.63 & -1.30 & 6.45 \\
Q. B4 & $1.2 \%$ & $7.1 \%$ & $65.9 \%$ & $25.9 \%$ & 4.15 & 0.65 & -1.24 & 5.78 \\
Q. B5 & $2.4 \%$ & $5.9 \%$ & $68.2 \%$ & $23.5 \%$ & 4.13 & 0.61 & -0.71 & 2.39 \\
Q. B6 & $1.2 \%$ & $10.6 \%$ & $64.7 \%$ & $23.5 \%$ & 4.11 & 0.62 & -0.38 & 0.92 \\
Q. B7 & $2.4 \%$ & $8.2 \%$ & $67.1 \%$ & $22.4 \%$ & 4.09 & 0.63 & -0.66 & 1.89 \\
\hline
\end{tabular}


answers shown in Table 4, the general total of teachers who participated in the research were in favor of socialization. Initially, $60.0 \%$ of the participants stated that they cultivate the development of positive attitudes of students without special needs towards students with autism. A very important factor in inclusive education is the socialization of children with special educational needs.

Inclusive education seeks a school open to all, without categorization and segregation, and thus promotes a set of values. The Greek educational system refers to a mainstream school where the basic values are equality among students. In this way it eliminates diversity and promotes human rights in order to avoid social exclusion [12]. Teachers with 58.8\% stated that they can treat students in a way that a child with autism feels accepted by others. Thus, the teacher through the integration should take care of the change of attitudes of the classmates in order to accept the children with autism. Then, $61.2 \%$ claimed that they create socializing conditions for a child with autism.

An important condition is the social integration of children with autism. Teachers through integration should create conditions for these children to integrate smoothly and socialize with their classmates. Therefore, the inclusion of children with autism in general school offers experiences and a first experience for social inclusion. $60.0 \%$ said they can effectively handle situations of disapproval of a child with autism by their classmates. Teachers face many challenges during integration, one of which is the treatment of children with autism by typical children. Children with autism are at the center of ridicule because of their uniqueness and sociability. As a result, these children do not feel safe and accepted. Thus, the teacher must properly nurture children of normal development so that they can accept and help these children. $54.1 \%$ of teachers said they accept one with a child with autism. This means that teachers are fully familiar with the term autism and accept these children into their classes.

A few years before the discovery of the concept of integration, these children were confronted with the social stigma of "abnormal" children, as society called them. Children with certain disabilities are no longer classified as "disabled" or "sick", other children with special educational needs.

The third research question was "Are teachers satisfied with their ability to diversify their teaching to meet the needs of students with ASD classes?" To

Table 4. Promoting socialization.

\begin{tabular}{|c|c|c|c|c|c|c|c|c|}
\hline & $\begin{array}{l}\text { I absolutely } \\
\text { disagree }\end{array}$ & $\begin{array}{l}\text { I neither agree } \\
\text { nor disagree }\end{array}$ & Agree & $\begin{array}{c}\text { Strongly } \\
\text { Agree }\end{array}$ & $\begin{array}{l}\text { Average } \\
\text { Price }(\mathrm{m})\end{array}$ & $\begin{array}{c}\text { Standard } \\
\text { Deviation }(\mathrm{Sd})\end{array}$ & Skewness & Kurtosis \\
\hline Q. B1 & $1.2 \%$ & $3.5 \%$ & $60.0 \%$ & $35.3 \%$ & 4.29 & 0.59 & -0.54 & 1.40 \\
\hline Q. B2 & $1.2 \%$ & $5.9 \%$ & $58.8 \%$ & $34.1 \%$ & 4.25 & 0.67 & -1.30 & 5.27 \\
\hline Q. B3 & $1.2 \%$ & $4.7 \%$ & $61.2 \%$ & $32.9 \%$ & 4.25 & 0.65 & -1.35 & 6.04 \\
\hline Q. B4 & $1.2 \%$ & $5.9 \%$ & $60.0 \%$ & $32.9 \%$ & 4.25 & 0.62 & -0.52 & 1.06 \\
\hline Q.B5 & $1.2 \%$ & $4.7 \%$ & $54.1 \%$ & $40.0 \%$ & 4.33 & 0.62 & -0.67 & 1.03 \\
\hline
\end{tabular}


answer this research question you will need questions focusing on differentiating teaching for children with autism. As can be seen from Table 5, the general set of primary school teachers argued that they could teach them in order to respond and keep pace with integration. $67.1 \%$ said that teachers differentiate the material to suit all children in the class, including children with autism. Also, again $67.1 \%$ stated that they are able to differentiate if the material is needed to meet all the children in the class with or without autism.

When asked if they differentiate their teaching to meet all children in the class with or without autism, $63.5 \%$ of teachers said they were able to do so. $64.7 \%$ argued that teachers differentiate the learning and consolidation activities of an object to meet all children with or without autism, while $62.4 \%$ believe that it is capable of differentiating the way it is assessed. From the above findings we understand that teachers are willing to diversify their teaching to help and integrate these children into the general school.

Differentiated teaching can be the means of effective teaching for all students. It is an interactive situation between the teacher and the student, through which the teacher responds to the special needs of the students, who are now called to actively participate, to learn continuously and to reach where they can potentially reach [61]. The teacher in order to carry out the educational integration in the best possible way should have a personalized program. Through this program he is called to connect his knowledge with the learning needs of the child and his experiences with the corresponding educational modules where he will need to do, to properly evaluate the educational practices and the effectiveness of his work. Its role is very difficult since they have to combine the needs of children with autism but also the needs of typical children [39].

The fourth research question was "Are teachers satisfied with their ability to work with the special educator?" To answer a specific research question will require the questions which focused on cooperation with the specialist teacher. As can be seen from Table 6, as far as the cooperation of teachers with other teachers is concerned, they show a positive image in the cooperation with the special educator for the integration of a child with autism in the classroom. In relation, $50.6 \%$ stated that they cooperate with the special educator for the integration of

Table 5. Differentiation.

\begin{tabular}{|c|c|c|c|c|c|c|c|}
\hline & $\begin{array}{l}\text { Nor do I agree } \\
\text { Nor do I disagree }\end{array}$ & Agree & $\begin{array}{l}\text { Strongly } \\
\text { Agree }\end{array}$ & $\begin{array}{l}\text { Average } \\
\text { Price }(\mathrm{m})\end{array}$ & $\begin{array}{c}\text { Standard } \\
\text { Deviation (Sd) }\end{array}$ & Skewness & Kurtosis \\
\hline Q. B1 & $3.5 \%$ & $67.1 \%$ & $29.4 \%$ & 4.26 & 0.52 & 0.29 & -0.33 \\
\hline Q. B2 & $2.4 \%$ & $67.1 \%$ & $30.6 \%$ & 4.28 & 0.50 & 0.39 & -0.57 \\
\hline Q. B3 & $3.5 \%$ & $63.5 \%$ & $31.8 \%$ & 4.26 & 0.58 & -0.46 & 1.61 \\
\hline Q. B4 & $3.5 \%$ & $64.7 \%$ & $31.8 \%$ & 4.28 & 0.53 & 0.20 & -0.50 \\
\hline Q. B5 & $3.5 \%$ & $62.4 \%$ & $32.9 \%$ & 4.26 & 0.64 & -1.41 & 6.78 \\
\hline
\end{tabular}


Table 6. Cooperation.

\begin{tabular}{cccccccc}
\hline & $\begin{array}{c}\text { Nor do I agree Nor } \\
\text { do I disagree }\end{array}$ & Agree & Strongly Agree & $\begin{array}{c}\text { Average } \\
\text { Price (m) }\end{array}$ & $\begin{array}{c}\text { Standard } \\
\text { Deviation (Sd) }\end{array}$ & Skewness & Kurtosis \\
\hline Q. B1 & $4.7 \%$ & $50.6 \%$ & $43.5 \%$ & 4.36 & 0.63 & -0.77 & 1.02 \\
Q. B2 & $4.7 \%$ & $55.3 \%$ & $40.0 \%$ & 4.35 & 0.57 & -0.18 & -0.70 \\
Q. B3 & $5.9 \%$ & $54.1 \%$ & $40.0 \%$ & 4.34 & 0.59 & -0.25 & -0.64 \\
Q. B4 & $3.5 \%$ & $55.3 \%$ & $41.2 \%$ & 4.38 & 0.56 & -0.13 & -0.83 \\
Q. B5 & $5.9 \%$ & $52.9 \%$ & $41.2 \%$ & 4.35 & 0.59 & -0.29 & -0.65 \\
Q. B6 & $3.5 \%$ & $55.3 \%$ & $40.0 \%$ & 4.33 & 0.66 & -1.49 & 6.21 \\
\hline
\end{tabular}

a child with autism in the classroom. Also, $55.3 \%$ of teachers say they can identify people they can turn to for support when there is a child with autism in the classroom. 54.1\% said they use current laws and regulations to improve the inclusion of a child with autism. Then, 55.3\% reported that they inform the parents of a child with an autopsy about their rights based on the current laws and regulations. $52.9 \%$ of the teachers stated that they work with the parents of a child with a disability for their more effective integration in the general class. $55.3 \%$ stated that they cooperate with the other general teachers who teach the child with autism who is included in their class.

Regarding the above, it becomes clear that the teachers cooperate smoothly with the special education teachers. According to the literature, collaborative teaching is understood as collaboration, the matching of a general education teacher and a special education teacher in order to jointly teach a heterogeneous set of students including typical and non-typical development, within the mainstream school and in such a way as to meet the learning needs of all students. It should be emphasized that the cooperation of the two teachers is different from the cooperation of the teachers of other specialties. A successful collaboration is implemented when the two teachers have full responsibility and contribute to each other in the planning and evaluation of teaching. Finally, the main role is played by the cooperation that the special education teacher will develop with the parents of the children, the mutual respect that will be created between them for their common goal of the school and social integration of the students [39].

The fifth research was "What are the views of teachers on the education of children with ASD in the special school and what are the basic conditions for the inclusion of a child with autism?" To answer this question, you will need questions that focus on the basic conditions for the inclusion of a child with autism. As shown in Table 7, teachers follow the basic prerequisites for successful integration. More specifically, $55.3 \%$ of primary school teachers stated that the basic condition for the effective integration of a child with autism is the attitude of the general education teacher. The percentage of $54.1 \%$ noted that the basic condition for a substantial integration with autism is the attitude of the classmates of the child with autism. Finally, with a percentage of $54.1 \%$, the teachers answered 
Table 7. Inclusion conditions.

\begin{tabular}{cccccccc}
\hline & $\begin{array}{c}\text { I neither agree } \\
\text { nor disagree }\end{array}$ & Agree & $\begin{array}{c}\text { Strongly } \\
\text { Agree }\end{array}$ & $\begin{array}{c}\text { Average } \\
\text { Price (m) }\end{array}$ & Standard Deviation (S.D) & Skewness & Kurtosis \\
\hline Q. B1 & $3.5 \%$ & $55.3 \%$ & $41.2 \%$ & 4.38 & 0.56 & -0.13 & -0.83 \\
Q. B2 & $7.1 \%$ & $54.1 \%$ & $37.6 \%$ & 4.28 & 0.65 & -0.62 & 0.68 \\
Q. B3 & $3.5 \%$ & $54.1 \%$ & $41.2 \%$ & 4.35 & 0.61 & -0.69 & 1.24 \\
\hline
\end{tabular}

that the basic condition for a substantial integration of a child with autism is the attitude of the child's family.

Regarding the literature, for the common education a basic condition is the cooperation of the whole community where the school is located. Those who make up the wider environment where integration takes place must work together and help the process. In this way they will support the creation of a framework with consistency and stability that is necessary for a child with autism. The teacher plays an important role as he should be able to accept the diversity of children at all levels. The inclusion and ability of a child with autism to integrate into a peer group depends on the duration of the early intervention. Also, the sensitivity and readiness of the teacher but also the smooth cooperation with the parents is the main basis for a successful integration.

The attitude of teachers and the flexibility of the school such as the building infrastructure, the appropriate equipment, the teaching material and the specialized staff, these are key factors for the integration of children with autism in the mainstream school. The school inclusion of children with autism can be implemented under the following conditions: early and valid diagnosis, early supportive intervention and the involvement of parents in early supportive intervention procedures. The diagnosis of a child with autism by the competent bodies and the decision to join a class is the first step for the educational program. The integration must start from the first school years of the child in order to have the right reaction. Young children have not come into contact with exclusion and with proper education they will be able to accept and understand diversity and thus reduce their rejection. The main criteria for the success of the integration are: the teachers, their attitudes and behaviors, their education, the cooperation of the parents with the school and most importantly the cooperation between the general and special educators. Mentioning a successful integration, teacher training is an integral part of it. Teachers must be constantly trained for the special educational needs but also for the new educational practices for these children. The right conditions for integration are an important opportunity for a society for all [45].

The sixth research question was "What are the teachers' views on the use of the medical and charitable model?" To answer this research question, the questionnaire used two categories of questions, the one for the medical model and the one for the charity model. Regarding the medical model as shown in Table 8, a general number of teachers were in favor of this model. Specifically, 57\% 
Table 8. Medical model.

\begin{tabular}{ccccccccc}
\hline & Disagree & $\begin{array}{c}\text { I neither agree } \\
\text { nor disagree }\end{array}$ & Agree & $\begin{array}{c}\text { Strongly } \\
\text { Agree }\end{array}$ & $\begin{array}{c}\text { Average } \\
\text { Price (m) }\end{array}$ & $\begin{array}{c}\text { Standard } \\
\text { Deviation (Sd) }\end{array}$ & Skewness & Kurtosis \\
\hline Q. B1 & $2.4 \%$ & $5.9 \%$ & $57.6 \%$ & $34.1 \%$ & 4.24 & 0.67 & -0.80 & 1.54 \\
Q. B2 & $1.2 \%$ & $9.4 \%$ & $58.8 \%$ & $30.6 \%$ & 4.18 & 0.69 & -1.13 & 4.04 \\
Q. B3 & $3.5 \%$ & $9.4 \%$ & $56.5 \%$ & $30.6 \%$ & 4.14 & 0.73 & -0.80 & 1.06 \\
Q, B4 & $4.7 \%$ & $15.3 \%$ & $51.8 \%$ & $27.1 \%$ & 3.99 & 0.85 & -0.92 & 1.23 \\
Q. B5 & $1.2 \%$ & $9.4 \%$ & $61.2 \%$ & $29.4 \%$ & 4.20 & 0.59 & -0.08 & -0.34 \\
\hline
\end{tabular}

stated that the basic condition for the inclusion of a child with autism is the number of special education periods he has received. Also, $58.8 \%$ of teachers said that a basic condition for the effective integration of a child with autism is the level of autism he has. In addition, $56.5 \%$ of the general education teachers support that the special education teacher should be primarily responsible for the integration of the child with autism who is included in a general education class. $51.8 \%$ state that the evaluation of a child with autism by the Special Education Committee is necessary for the class teacher to start dealing with the child's education. Finally, with a percentage of $61.2 \%$, the teachers report that the specialists who deal with a child with autism know how to deal with it.

In relation to the literature the medical model includes the perceptions, behaviors and medical approaches where they identify the disorder. From this perspective the disorder is identified as an individual pathology. Diagnosis is the main tool for classifying the population and determines the individual's access to social services. Sometimes this model considers the individual incapable or limited to cope with his role and obligations. The medical model gives priority to the detection of the malfunction, in order to follow an appropriate medical and educational intervention.

As far as the school context is concerned, teachers of both special and general education must be fully informed about the child's condition and dysfunction in order to be able to apply appropriate practices for it. The evaluation by the SE is a necessary condition for the teacher to start and create the individualized program of the child but also the cooperation with the special teacher and with the parents. Teachers need to learn to work together so that a smooth integration can take place without many obstacles for the child with autism. Of course, the special educator who has the training he/she has can carry out the educational integration in the best possible way should have specific reasons, such as the teaching assistant, the supervisor, the coach, the mentor and many more. The task he/she is called to do is to connect his/her knowledge with the needs of the child and his/her experiences with the respective teaching units where he/she will need to do, to properly evaluate the educational practices and the effectiveness of his/her work and to cooperate with the rest scientific staff to achieve the best outcome for the integration of these children (Ioannidis et al., 2010) [39]. 
Regarding the charitable model, teachers seem to be in favor of this model and to incorporate it into the educational process. As shown in Table 9, 51.8\% of general education teachers argue that the school should cultivate a sense of charity towards children with autism and $55.3 \%$ said that the main purpose of including a child with autism in general school should be its socialization. More specifically, children with autism have difficulties in socially understanding and recognizing emotional states. Therefore, these children face problems in their socialization and interaction with their peers.

Social inclusion is considered very important since these children must learn to participate in various activities, to conquer mutual personal relationships and the feeling of belonging. The acceptance aspect of a person with autism includes recognizing their personality rather than their disorder, as well as the positive reactions of others. In addition to acceptance, which is very important, access to education is one of the positive factors for the smooth social integration of children with autism. The inclusion of children with autism in mainstream school brings with it the principles of respect and equality for these children and thus defines a sense of belonging to all students, security, friendships and social interaction. The social inclusion of children with autism is very important. The difficulties faced by students with autism at the social level are solved in the context of inclusive education, taking into account the opinion of the children themselves regarding the formation of educational frameworks, their personal desires for their social interactions and the type of educational support provided to them.

The socialization of children with autism is presented as a multidimensional concept with various parameters. Acceptance by peers, friendships and membership in a peer group are different aspects of students' social position in the classroom. When acceptance by peers is low, social relationships and the formation of friendships between peers are negatively affected. The degree of non-acceptance by peers can predict long-term problems in social adjustment, as making friends is an important parameter for the development of children's social skills and self-esteem. Also, having the student as a member of a group and having a central position in it is equally important for the evaluation and the degree of his social development. Friendships are a prerequisite and serve as a basis for learning social skills and handling close relationships, which in turn are important for claiming a place in a group of peers. The social status popularity of students in the social network of their class, the difference between the social status of children (as an indication of popularity) and their social participation

Table 9. Charitable model.

\begin{tabular}{ccccccccr}
\hline & Disagree & $\begin{array}{c}\text { I neither agree nor } \\
\text { disagree }\end{array}$ & Agree & $\begin{array}{c}\text { Strongly } \\
\text { Agree }\end{array}$ & $\begin{array}{c}\text { Average } \\
\text { Price (m) }\end{array}$ & $\begin{array}{c}\text { Standard Deviation } \\
\text { (S.D) }\end{array}$ & Skewness & Kurtosis \\
\hline Q. B1 & $1.2 \%$ & $8.2 \%$ & $37.6 \%$ & $51.8 \%$ & 4.38 & 0.79 & -1.53 & 3.38 \\
Q. B2 & $1.2 \%$ & $5.9 \%$ & $37.6 \%$ & $55.3 \%$ & 4.47 & 0.67 & -1.13 & 1.19 \\
\hline
\end{tabular}


in the social network of their class is strongly pointed out.

Popularity is used as a similar concept and is defined as the expression of liking or dissatisfaction by a whole towards an individual. Social participation is an element of the reciprocity of social relations, the acceptance of children by a subgroup and the degree of their effective participation in it. It also proves to be an important factor in assessing students' emotional and social development. Thus, teachers through their work must cultivate the feeling of charity towards children with autism. With this goal, the children of formal development will be able to perceive the particularities of these students and to "embrace" them [12]. The general class teacher should be able to gradually integrate into the classroom, since the school reflects the society and therefore if there is a smooth transition to school there will be in society later. In conclusion, from the above the main purpose of the inclusion of a child with autism in the mainstream school should be his socialization.

\section{Conclusions}

In the present study, the inclusion of children with autism in the mainstream school class was studied. The findings of the research on the views of primary school teachers draw some conclusions. Initially, it was observed that teachers know the legislation quite well and that they can use it to operate within the mainstream school. Teachers identify the symptoms of children with autism and thus follow the referral process for evaluation; this has to do with the fact that younger teachers, as shown by the demographic data of the research, are increasingly trained with postgraduate studies and training seminars in relation to special education about the continuous study of new research and the knowledge of existing legislation.

Teachers understand that children with autism need an individualized intervention program and that they are in favor of inclusive education. Thus, the research of Laze [46] agreed that teachers who hold a master's degree or a specialization have more knowledge on the subject of autism and integration into the legal framework. As far as the organization of effective integration is concerned, teachers organize an effective integration since I believe that children with autism through this process can develop other aspects of their character. Thus, they feel more accepted and that they can later integrate smoothly into society [10]. Therefore, teachers adapt the teaching process to the needs of the children in their classroom.

The teacher must understand the different needs of the students and adjust the material with the appropriate stimuli so that the student finds interest in the teaching process. The teacher is called to connect the knowledge with the needs of the child and his/her experiences with the respective teaching units where he/she will need to do, to properly evaluate the educational practices and the effectiveness of his/her work [39].

In addition, the research of Exarchos [48] shows that teachers are positive in the integration of children with autism in the mainstream school and thus shape 
the educational program according to the needs of students. However, the teachers stated that the lack of material and technical infrastructure does not help the work of the teachers so much. The results of the research showed that primary school teachers promote the socialization of children with autism. Through research, teachers cultivate the development of positive attitudes of students without special needs towards students with autism.

A very important factor in inclusive education is the socialization of children with special educational needs. Inclusive education seeks a school open to all, without categorization and segregation, and thus promotes a set of values. In this way, teachers eliminate diversity and create a school for all [12]. According to them, the teachers create conditions for socialization, since the integration in the mainstream school offers experiences and possibilities to the specific children. As far as the disapproval of these children is concerned, teachers can handle such situations and can create a climate of cooperation between students.

Regarding Laze's research [46] he agrees with this research since the results showed that more opportunities are provided for the socialization of children with autism in mainstream school. The research of Bosch [50] is also in agreement since the secondary school teachers and the special education teachers consider the integration of children with autism in the general school very important since they believe that it will benefit them in many areas of his life. Teachers stated that they are satisfied with their ability to differentiate teaching, so through the analysis of the questionnaires teachers differentiate the material to meet all children in the class including children with autism, so they are able to diversify the material to respond to all students without restriction, as they believe that differentiated learning and consolidation activities will not only help children with autism in the learning process but also in cooperation and group empowerment.

These data are in the same function as the literature since differentiated teaching is effective teaching for all students. It is a procedure between the student and the teacher where the teacher is called to show the possibilities to the student and place them in the course [61]. Regarding the cooperation between the teachers and the special teachers, it seems that there is good cooperation between the two specialties. Teachers have the ability to identify and address the right specialties to help them with children with autism. Regarding it, it seems that the teachers have very good communication with the parents of these children and include them in the educational process. Collaboration between specialties is a powerful weapon of integration, as a successful collaboration helps the development of children and makes the work of teachers easier and curriculum design becomes complete.

On the contrary, from the specific research in the research of Nerantzidou [47] it seems that it is difficult for the teachers to cooperate; the special guides are not involved in the integration process and thus confusion is created in the program. Regarding the basic conditions for the integration of children with autism, teachers believe that the basic condition for effective integration is the attitude of 
the general education teacher, as well as the attitude of classmates towards the child with autism. As mentioned by Majoko [49] in her research, teachers showed uncertainty about the inclusion of children with autism in the general school since there are many conditions where they have to face. Thus, they stated that it would help to integrate a school psychologist in order to help themselves and children with autism for their smooth integration in the mainstream school.

Regarding the medical model, the teachers stated that the special educator should be primarily responsible for the integration of the child with autism who is part of a general class. More specifically, they stated that the evaluation of a child with autism by the Special Education Committee is necessary for the class teacher to start dealing with the child's education. Finally, as far as the charitable model is concerned, teachers cultivate a sense of charity towards children with autism, so they argued that the main purpose of enrolling a child with autism in mainstream school should be to socialize them.

Laze's research [46] agrees, stating that children with autism have the right to education in mainstream school, as it will help them in their socialization. Social inclusion is considered very important since in this area, children with autism lag behind and with their inclusion in the mainstream school will meet people of their age and will gain mutual personal relationships. This will not only help children with autism but also typical children as they will create positive attitudes for these children. In conclusion, from the above findings, it becomes clear that teachers have a positive attitude towards the inclusion of children with autism in mainstream schools.

\section{Suggestions and Restrictions}

The specific research that was carried out helped to extend the existing knowledge about the inclusion of children with autism in the general school. A major limitation of the research was the length of time. The researcher had a specific time to collect information and her sample and so was limited to specific information and a small sample. During the research process, everything worked satisfactorily both the data collection and the processing of the results, except for the fact that while convenient sampling was selected there was difficulty for the participants to give their consent to participate in the research process. Due to the global pandemic, the researcher could only reach the participants electronically [62] and thus was limited to finding the right sample for the research of children with autism in general school, since the practices and plans over the years differ and as far as the autism part is concerned, research is a continuation of this disorder. In addition, an ongoing observation could be made in schools where children with autism are enrolled to observe how teachers follow and create individualized programs.

\section{Acknowledgements}

This study would not have been possible without the contribution of numerous 
people. We would like to thank the educational staff who took part in the research.

\section{Conflicts of Interest}

The author declares no conflicts of interest.

\section{References}

[1] Mastrogiannis, A. and Xanthopoulou, E. (2015) Management and Treatment of Autism through Parallel Support Procedures. Proceedings of the 5th Panhellenic Conference of Educational Sciences, Athens, 19-21 June 2015, 1-19.

https://eproceedings.epublishing.ekt.gr/index.php/edusc/article/view/160/126

[2] Panteliadou, S., Filippatou, D. and Xenaki, Ch. (2013) Differentiated Teaching: Theoretical Approaches and Educational Practices. Pedio, Athens.

[3] Antoniou, A.S., Geralexis, I. and Charitaki, G. (2017) Special Educators' Teaching Self-Efficacy Determination: A Quantitative Approach. Psychology, 8, 1642-1656. https://doi.org/10.4236/psych.2017.811108

[4] Charitaki, G., Soulis, S.G. and Tyropoli, R. (2019) Academic Self-Regulation in Autism Spectrum Disorder: A Principal Components Analysis. International Journal of Disability, Development and Education, 1-18. https://doi.org/10.1080/1034912X.2019.1640353

[5] Barton, L. (2008) The Policy of Inclusion. Ellinika Grammata, Athens.

[6] Garner, P. and Davies, J.D. (2001) Introducing Special Needs: A Companion Guide for Student Teachers. David Fulton Publishers, London.

[7] Zionou-Sideri, A. (1998) The Disabled and Their Education: A Psycho-Pedagogical Approach to Integration. Ellinika Grammata, Athens.

[8] Vlachou-Balafouti, A. and Zoniou-Sideris, A. (2000) Greek Policy in the Area of Special Inclusive Education. David Fulton Publishers, London.

[9] Zoniou-Sideris, A. (2004) Contemporary Accession Approaches. Ellinika Grammata, Athens.

[10] Panopoulou-Maratou, O. (2009) Children with Diffuse Developmental Disorders and Integration. Ellinika Grammata, Athens.

[11] Kourkoutas, H. (2010) Inclusion Policies and Modern Special Education: Theoretical Issues and Empirical Studies. Laboratory of Intercultural and Immigration Studies, Rethymnon.

[12] Avramidis, I. and Dialektaki, K. (2010) Changing Teachers' Attitudes towards Inclusion: From the Ideology of Authority to the Authentic Application of Inclusive Education. Pedio, Athens.

[13] Stasinos, D. (1991) Special Education in Greece. Perceptions, Institutions and Practices, State and Private Initiative (1906-1989). Gutenberg, Athens.

[14] Tzouriadou, M. (1995) Children with Special Educational Needs. A Psycho-Pedagogical Approach. Promitheus, Thessaloniki.

[15] Antonopoulos, G. (2003) Inclusive Education for All. A Human Rights Issue or a New Political Orthodoxy. Athens.

[16] Law 2817/2000 (Government Gazette 78-A-14-3-2000) Education of Persons with Special Educational Needs.

[17] Soulis, S.G. (2002) Pedagogy of Integration: From the School of Segregation to a 
School for All. Vol. A, Typothito, Athens.

[18] Zoniou-Sideris, A. (2011) People with Special Needs and Their Integration. Pedio, Athens.

[19] Law 3699/2008 (Government Gazette 199-A-2-10-2008) Special Education and Training of Persons with Disabilities or Special Educational Needs.

http://www.pi-schools.gr

[20] Deropoulou-Derou, E. (2012) Assessing the Course of Legislative Changes Thirty Years after the Enactment of the First Law on Special Education in Greece. In: Zoniou-Sideris, A., Ed., Parallel Support for Children with Autism Spectrum Disorders 161 A. Deropoulou-Derou and A. Vlachou-Balafouti (Eds.) Disability and Educational Policy, Pedio, Athens, 123-151.

[21] Angelidis, P. and Avramidou, L. (2011) Development of Inclusive Education through Non-Formal Learning Environments. Diadrasi, Athens.

[22] Tafa, E. (2010) Co-Education of Children with and without Learning and Behavioral Problems. Ellinika Grammata, Athens.

[23] Salvaras, G. and Salvara, M. (2011) Teaching Models and Strategies: Construction and Use of Teaching Tools. Diadrasi, Athens.

[24] Karagianni, P. (2004) Educational Practices for the Integration of Children with Special Educational Needs in the General School. Ellinika Grammata, Athens.

[25] Avramidis, I., Antoniou, A., S., Garanis, A., Goudiras, D., Efstathiou, M., Darais, K., Zymbrakakis, I., Kampoli, G., Koukouta, A., Kousoureta, N., Liontou, G., Messaritakis, V., Bakopoulou, G., Nanou, A., Panera, A., X., Patsidou-Iliadou, M., Soulis, S., Symeonidou, S., Tsipouras, S., Ftiaka, E., Chariopolitou, A. and Saridou, Ch. (2013) From Special Education to Inclusive Education: From School to a Society for All. Graphima, Thessaloniki.

[26] American Psychiatric Association. (1994) Diagnostic and Statistical Manual of Mental Disorders. Fourth Edition Revised, American Psychiatric Association Publishing, Washington DC.

[27] American Psychiatric Association (2013) Diagnostic and Statistical Manual of Mental Disorders. Fifth Edition Revised, American Psychiatric Association Publishing, Washington DC. https://doi.org/10.1176/appi.books.9780890425596

[28] Gonella, E. (2006) Autism: An Enigma and Reality. From the Theoretical Approach to the Educational Intervention. Odysseus, Athens.

[29] Peklari, E. (2019) Mathematical Skills in Autism Spectrum Disorder. Asian Journal of Applied Science and Technology, 3, 111-123.

[30] Nova, Ch. (2015) Comparative Approach to the Aggressive Behavior of Children with Autism in School Age. Proceedings of the 5 th Panhellenic Conference of Educational Sciences, Athens, 19-21 June 2015, 1-17.

https://eproceedings.epublishing.ekt.gr/index.php/edusc/article/viewFile/244/209

[31] Seretopoulos, K., Lamnisos, D. and Giannakou, K. (2020) The Epidemiology of Autism Spectrum Disorders. Archives of Greek Medicine, 37, 169-180. http://mail.mednet.gr/archives/2020-2/pdf/169.pdf

[32] Firth, U. (1994) Autism: Explaining the Riddle. Ellinika Grammata, Athens.

[33] Lennard-Brown, S. (2004) Autism. Savvalas, Athens.

[34] Wing, L. (1996) Autism Spectrum Disorders: A Guide to Diagnosis. National Autistic Society, Athens.

[35] Happe, F. (2003) Autism. Contemporary Psychological View. Gutenberg, Athens. 
[36] Wall, K. (2010) Autism and Early Year Practice. Sage, London. https://doi.org/10.4135/9781446279557

[37] Syriopoulou-Delli, Ch. (2011) Diffuse Developmental Disorders: Psychology-Pedagogy-Sociology. Grigori, Athens.

[38] Sinanidou, D.M. (2013) Autism: Parental Counseling, the Role and Functions of the Unified School. ION, Athens.

[39] Ioannidis, V. and Kalokairinou-Anagnostopoulou, A. (2010) Special Education and Training: An Approach for Education Executives and Health Professionals. Beta Medical Publications, Athens.

[40] Vogiatzi, X.A., Charitaki, G. and Kourkoutas, E. (2021) Assessing Psychometric Properties of the Sentiments, Attitudes and Concerns about Inclusive Education Scale in a Greek-Speaking Sample of In-Service Teachers. Tech Know Learn.

https://doi.org/10.1007/s10758-021-09554-x

[41] Imellou, O. (2003) Mild Learning Disabilities: Approaches to the General School. A Psycho-Pedagogical Approach to Integration. Pedio, Athens.

[42] Kaiseroglou, N. (2010) People with Special Educational Needs (PWD) in General Education Schools in Primary Education: Issues and Possibilities of Internal Educational Policy. Private Edition, Thessaloniki.

[43] Bania, F., Antoniou, A.S., Theodoritsi, M., Theodoritsi, I., Charitaki, G. and Billis, E. (2019) Interaction with Disabled Persons Scale (IDPS): Translation and CrossCultural Validation in Greek. Disability and Rehabilitation, 43, 1-8. https://doi.org/10.1080/09638288.2019.1643420

[44] Bania, F., Gianniki, M., Giannakoudi, S. and Charitaki, G., Matzaroglou, C. and Billis, E. (2020) The Interaction with Disabled Persons Scale (IDPS): Evidencing Construct Validity with Factor Analysis and Measurement Invariance in Greek-Speaking Healthcare Students. Disability and Rehabilitation, 1-11. https://doi.org/10.1080/09638288.2020.1850890

[45] Magaliou, E. and Tsakpini, K. (2007) Educational Interventions for the Integration of People with Autism in School and in the Workplace-Structured Teaching. Graphima, Thessaloniki.

[46] Laze, S. (2019) Knowledge and Perceptions of Teachers of General and Special Education for the Integration of Children with Autism in the Regular Class of the General School. Postgraduate Work. University of Patras, Patras.

[47] Nerantzidou, A. (2011) Children with Autism in Integration Classes: Views and Experiences of Kindergarten Teachers. Postgraduate Work. University of Thessaloniki, Thessaloniki. http://ikee.lib.auth.gr/record/127182/files/GRI-2011-7220.pdf

[48] Exarchou, E. (2020) The Education of Students with Autism Spectrum Disorder (ASD): The Views-Perceptions of General and Special Education Teachers about the Inclusion-Co-Education of Students with ASD in the Formal Education Class in General Education Schools. Postgraduate Work. University of Ioannina, Ioannina. https://olympias.lib.uoi.gr/jspui/bitstream/123456789/29741/1/\%CE\%20\%9C.\%CE \%20\%95.\%20\%CE\%95\%CE\%9E\%CE\%91\%CE\%A1\%CE\%A7\%CE\%9F\%CE\%A5\%2 0\%CE\%95\%CE\%A5\%CE\%91\%CE\%93\%CE\%93\%CE\%95\%CE\%9B\%CE $\% 99 \% \mathrm{CE} \% 9$ 1\%202020.pdf

[49] Majoko, T. (2018) Inclusion of Children with Autism Spectrum Disorders in Mainstream Primary School Classrooms: Zimbabwean Teacher's Experiences, University of South Africa. https://files.eric.ed.gov/fulltext/EJ1196716.pdf

[50] Bosch, M.E. (2016) Examining the Attitudes of Secondary General Education and Special Education Teachers toward Inclusion of Children with Autism in General 
Education Classrooms. Barton College, Barton. https://files.eric.ed.gov/fulltext/EJ1129703.pdf

[51] Papanastasiou, E. and Papanastasiou, K. (2005) Methodology of Educational Research. Private, Athens.

[52] Kyriazopoulos, P. and Samantha, E. (2011) Research Methodology for the Elaboration of Diploma Theses. Modern Publishing Ltd., Athens.

[53] Tsiolis, G. (2011) The Relationship between Qualitative and Quantitative Research in the Social Sciences: From the War of "Examples" to Complex Approaches. Pedio, Athens.

[54] Zafeiropoulos, K. (2005) How Is a Scientific Research Done? Scientific Research and Paper Writing. Kritiki, Athens.

[55] Vamvoukas, M.I. (2010) Introduction to Psychopedagogical Research and Methodology. Grigoris, Athens.

[56] Vassileiou, E. and Charitaki, G. (2016) Investigating the Views of the Teachers of General Class for the Integration of Students with Special Learning Needs. PanHellenic Conference on Education Sciences, Vol. 1, 236-248.

[57] Latinopoulos, P. (2010) The First Steps in Research. A Useful Guide for Young Researchers. Kritiki, Athens.

[58] Nova-Kaltsouni, Ch. (2006) Methodology of Empirical Research in the Social Sciences. Gutenberg, Athens.

[59] Antoniou, A.S. (2006) Ethical Requirements and Codes of Ethics against Conducting Research in a Psychological Field. Journal of Philosophy, 1, 68-81.

https://file://C:/Users/700B 1/AppData/Local/Temp/22650-59651-1-PB.pdf

[60] Cohen, L., Manion, L. and Morrison, K. (2008) Educational Research Methodology. Metaichmio, Athens.

[61] Tomlinson, C. (1999) The Differentiated Classroom: Responding to the Needs of All Learners. ASCD, Alexandria.

[62] Tzivinikou, S., Charitaki, G. and Kagkara, D. (2020) Distance Education Attitudes (DEAS) during Covid-19 Crisis: Factor Structure, Reliability and Construct Validity of the Brief DEA Scale in Greek-Speaking SEND Teachers. Technology, Knowledge and Learning, 26, 461-479. https://doi.org/10.1007/s10758-020-09483-1 